\title{
New perspectives on carbonate mineral behaviour for carbon accounting and carbon utilization
}

\author{
SIOBHAN A. WILSON ${ }^{*}$, CONNOR C. TURVEY², \\ BREE MORGAN ${ }^{3}$, JIE CHENG', MAIJA J. RAUDSEPP', \\ JESSICA L. HAMILTON ${ }^{4}$, JENINE MCCUTCHEON ${ }^{s}$, \\ GORDON SOUTHAM ${ }^{\circ}$, IAN M. POWER ${ }^{7}$, NINA ZEYEN \\ AND STEWART J. FALLON ${ }^{*}$
}

University of Alberta, Edmonton, AB, Canada

(*correspondence: sawilson@ualberta.ca)

2 The University of British Columbia, Vancouver, BC,

\section{Canada}

${ }^{3}$ The University of Sydney, Camperdown, NSW, Australia

4 The Australian Synchrotron, Clayton, VIC, Australia

University of Waterloo, Waterloo, ON, Canada

- The University of Queensland, St Lucia, QLD, Australia

Trent University, Peterborough, ON, Canada

- Australian National University, Canberra, ACT, Australia

Understanding carbonate mineral behaviour is important for ensuring long-term carbon storage, accurate carbon accounting, and safe utilization of mineral products. Here, we provide some new perspectives on the behaviour of carbonate-bearing minerals within the context of Carbon Capture, Utilization and Storage (CCUS).

Our experiments and field studies show that atmospheric water vapour plays an essential role in mediating the amorphous-to-crystalline transition and hydrated carbonate phase transitions in water-undersaturated conditions. The decomposition of amorphous and crystalline carbonate phases occurs via humidity-mediated dissolutionprecipitation in thin films of adsorbed water at grain surfaces. Low humidity conditions stabilize some crystalline phases to unexpectedly high temperatures (e.g., lansfordite remains stable at room temperature and $\mathrm{RH}<20 \%$ for at least 7 years) whereas high humidity causes rapid decomposition or crystallization. Storage of amorphous carbonate phases under low humidity decreases their rate of crystallization. Our observations indicate that fractional crystallization of amorphous Mg-carbonate (AMC) and $\mathrm{Ca}-\mathrm{Mg}$-carbonate (ACMC) can take months to years at $\mathrm{RH}<30 \%$. Notably, we show that much of the $\mathrm{CO}_{2}$ stored in at least one mine tailings storage facility is in the form of AMC. Our results suggest that amorphous carbonate phases may play a greater role in CCUS, during enhanced weathering of alkaline rocks and mineral wastes, than previously anticipated. 